\title{
UAV application to estimate oil palm trees health using Visible Atmospherically Resistant Index (VARI) (Case study of Cikabayan Research Farm, Bogor City)
}

\author{
Medina Nur Anisa ${ }^{1}$, Rokhmatuloh $^{1 *}$, and Revi Hernina ${ }^{1}$ \\ ${ }^{1}$ Department of Geography, Faculty of Mathematics and Natural Science, Universitas Indonesia, \\ Depok, 16424, Indonesia
}

\begin{abstract}
This article describes the making of an oil palm tree health map using aerial photos extracted from UAV DJI Phantom 4. A DJI Phantom 4 was flown at 100 meters height at the Cikabayan Research Farm, Bogor City. Raw aerial photos from DJI Phantom 4 were processed using Agisoft Photoscan software to generate dense point clouds. These points were computed to produce a digital surface model (DSM) and orthophotos with a spatial resolution of $2.73 \mathrm{~cm} /$ pixel. Red, green, and blue bands of the photos were computed to provide the Visible Atmospherically Resistant Index (VARI). Also, orthophotos containing oil palm trees were digitized to create points in vector form. VARI pixel values were added to each point and classified into four classes: Needs Inspection, Declining Health, Moderately health, and Healthy. Resulted oil palm tree health map reveals that most of the oil palm trees in the study location are classified as Declining Health and Needs Inspection. Profitably, plantation workers can directly inspect oil palm trees whose health are declining, based on information derived from oil palm tree health map. The information that comes from this study will significantly save time and effort in monitoring oil palm trees' healthiness.
\end{abstract}

\section{Introduction}

The development of oil palm plantations is a strategic issue that encourages and improves the community's welfare, the national economy, and makes Indonesia the largest producer of palm oil [1]. It is envisaged that the development of oil palm plantations can open up business opportunities and increase employment. With this development, it is not surprising that the Indonesian palm oil industry has become a topic of interest to the world community.

Trees maintenance is crucial to determine whether the plants are healthy or sick to increase oil palm plantations. Plants with the disease will be treated or replaced with new plants to increase oil palm production. Monitoring oil palm plantations traditionally will require a lot of time and effort. Therefore cheaper and more efficient technological innovations are needed.

\footnotetext{
* Corresponding author: rokhmatuloh.ssi@sci.ui.ac.id
} 
Unmanned Aerial Vehicles (UAV) or Drone mapping technology is an alternative option besides other mapping technologies such as large and manned aerial photography and satellite-based mapping. UAV is a type of aircraft controlled by a remote control system tool via radio waves. The UAV is an electro-mechanical-based system that can carry out programmed missions with the characteristics of a flying machine that functions remotely by the pilot or can control himself, using aerodynamics' laws to lift himself [2].

UAV technology can be used to estimate vegetation cover [3], monitoring forest rehabilitation [4], forest fires [5], and monitoring forest health [6]. The drone has many advantages when compared to other remote sensing platforms such as planes and satellites. These advantages include cloud-free images and higher spatial resolution. UAV technology has the potential to be used for particular mapping purposes in agriculture [7]. Considering all the benefits mentioned earlier and the advantages of UAVs, this study uses UAVs' ability to monitor the health of oil palm trees. Not to mention that UAV applications can save time and increase productivity. Therefore, this study aims to estimate oil palm trees' health using the Visible Atmospheric Resistant Index (VARI) by utilizing aerial mapping technology.

\section{Method}

In this study, the oil palm plantations will be monitored using visible wavelengths generated from Unmanned Aerial Vehicles (UAV). The visible wavelengths were processed to generate the Visible Atmospherically Resistant Index (VARI), which would be used as a health indicator of oil palm trees.

\subsection{Research locations}

Cikabayan Research Farm is located at $6^{\circ} 33^{\prime} 5.06^{\prime \prime S}$ and 106 $43^{\prime} 3.78^{\prime \prime E}$. It is relatively close to the IPB University campus, close to the housing for lecturers (Figure 1). When seen in Figure 1, Cikabayan Research Farm is located north of the IPB University campus. This research farm has the largest area when compared to other research farms. Cikabayan Research Farm has around 22 hectares with a significant land area of approximately 5 hectares.

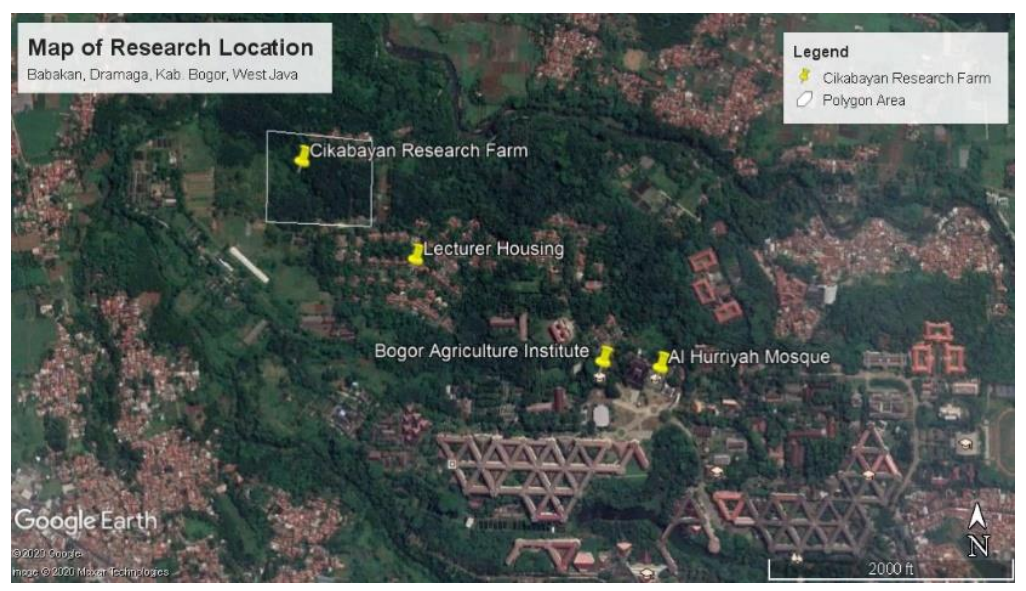

Fig. 1. Map of Research Location (Cikabayan Research Farm). (source: Google Earth) 


\subsection{Field data}

In recording field data using a rotor type UAV [8], a DJI Phantom 4 was flown in the study area (Figure 2). Before recording, a flight path was planned using the Pic 4D application on the mobile phone (Figure 3). This recording time took 9 minutes with a flying altitude of 100 meters above ground to get detailed and precise data with a spatial resolution of 2.73 $\mathrm{cm} /$ pixel.

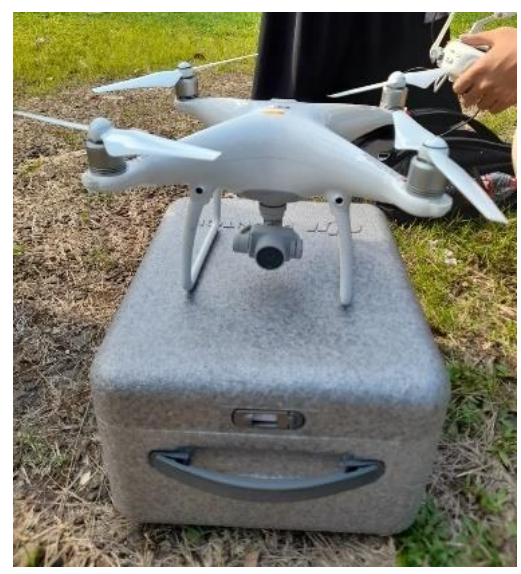

Fig. 2. DJI Phantom 4. (Personal Data)

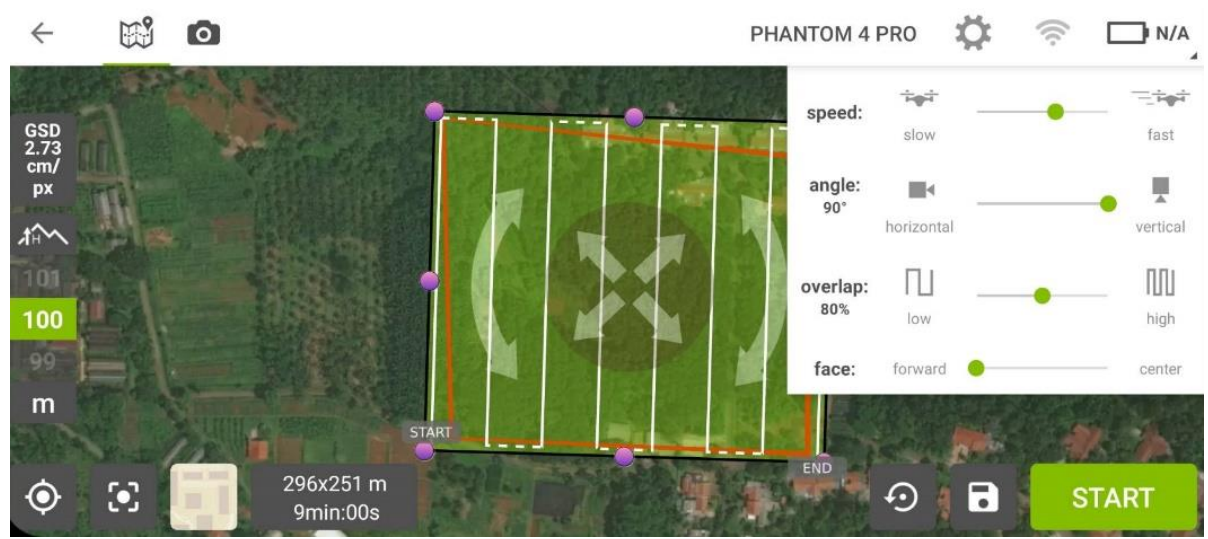

Fig. 3. Flightpath mission planning on Pic 4D mobile application. (Data Processing)

\subsection{Data processing}

After the recording phase, a JPEG format photo was obtained equipped with geographic coordinates. Approximately 80 photos were acquired from the UAV flight and combined using a photo mosaic process in the Agisoft Photoscan software. Combined photos were aligned to create dense point clouds. These points were calibrated to generate a mesh that provided a digital surface model (DSM) [9] and orthophotos. Orthophotos were converted into a tiff file extension using ArcGIS Pro software. 


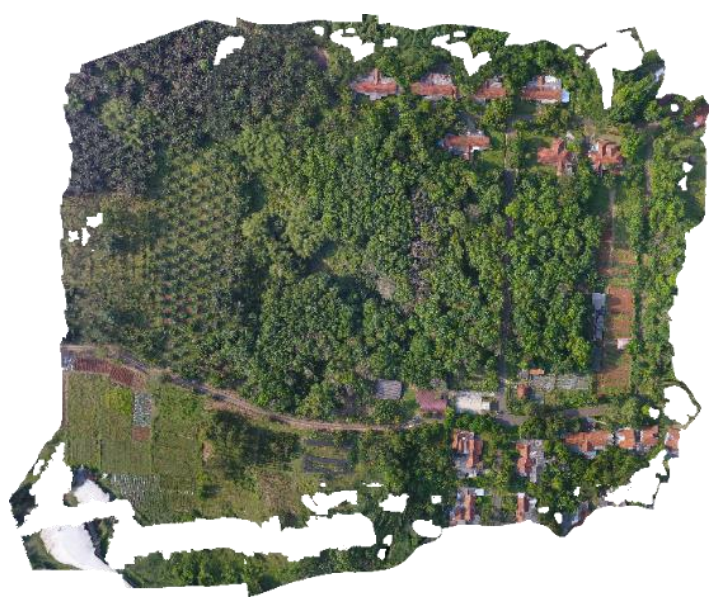

Fig. 4. The orthophoto in .tiff file. (Data Processing)

\subsection{Digitizing oil palm trees}

The orthophoto was digitized using ArcGIS Pro software to create and manage label objects [10]. All oil palm trees were digitized to generate circular polygons based on the size, shape, and characteristics extracted from aerial photographs. Next, digitized polygons were extracted into points and saved.

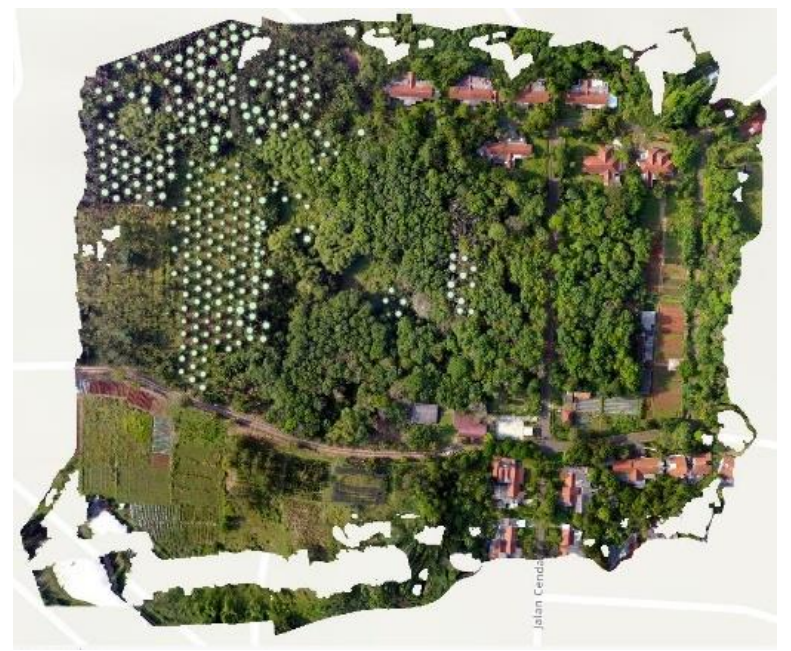

Fig. 5. Digitized polygons of all oil palm trees. (Data Processing)

\subsection{Raster processing}

After the digitization process was completed, the next process was to estimate oil palm trees' health using VARI. VARI is an indirect measure developed from the Leaf Area Index (LAI) and Vegetation Fraction (VF) based on visible wavelengths' reflectance values. VARI can be calculated using the following formula:

$$
\mathrm{VARI}=(\mathrm{Rg}-\mathrm{Rr}) /(\mathrm{Rg}+\mathrm{Rr}-\mathrm{R}(\mathrm{Rg}-\mathrm{Rb}))
$$


$\mathrm{Rr}, \mathrm{Rg}$, and $\mathrm{Rb}$ reflect values for the red, green, and blue bands, respectively [11].

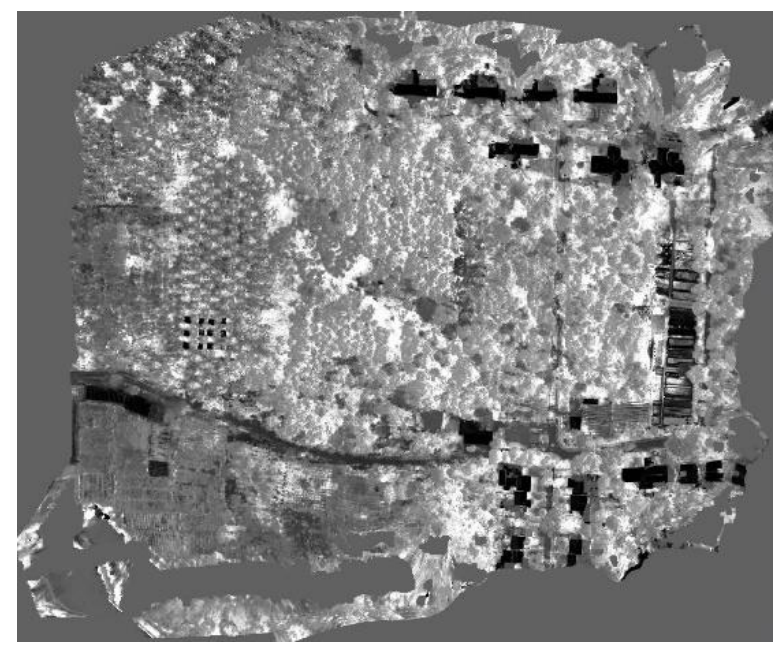

Fig. 6. Map with VARI pixel values. (Data Processing)

A raster function containing band arithmetic was used to display the map resulted from VARI computation. Parameters containing the VARI method were selected in the analysis step. When the parameter index shows red, green, and blue bands, fill in the index band with 1 for red, 2 for green, and 3 for blue. The standard deviation menu was chosen to increase the sharpness of the stretched image.

A raster map showing VARI was beneficial but could not be used to determine which trees need maintenance. Hence, it was necessary to have the average VARI value for each tree by extracting the VARI raster map using circular polygons. It could finally show healthy trees and which trees needed treatment.

\section{Results and discussion}

Resulted from VARI values are divided into four classes: Needs Inspection, Declining Health, Moderately health, and Healthy. Furthermore, each class is symbolized by gradation colors (red-yellow-green) to differentiate healthy trees from trees that need maintenance (Figure 8). The resulting oil palm tree health map in the Cikabayan Research Farm reveals that most oil palm trees are in Declining Health and Needs Inspection. Plantation workers can directly inspect oil palm trees whose health is declining, based on information derived from oil palm tree health map. The information that comes from this study will significantly save time and effort in monitoring oil palm trees' health.

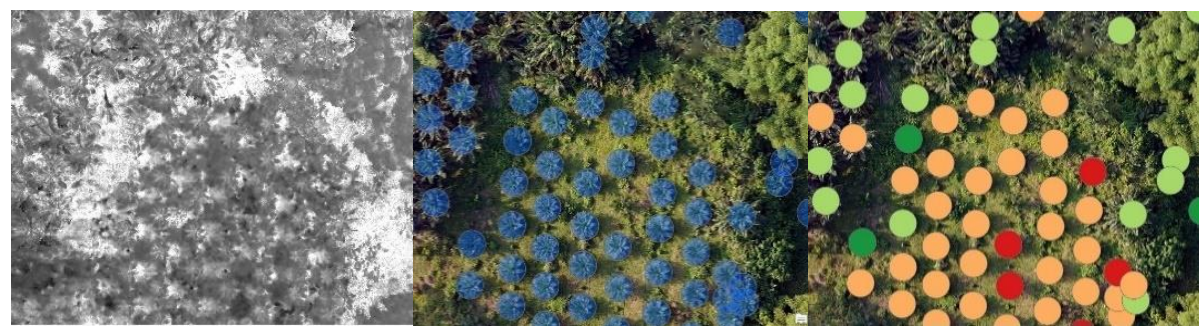

Fig. 7. The process of Vegetation Health Estimation (VARI, Extract, and Classes). (Data Processing) 


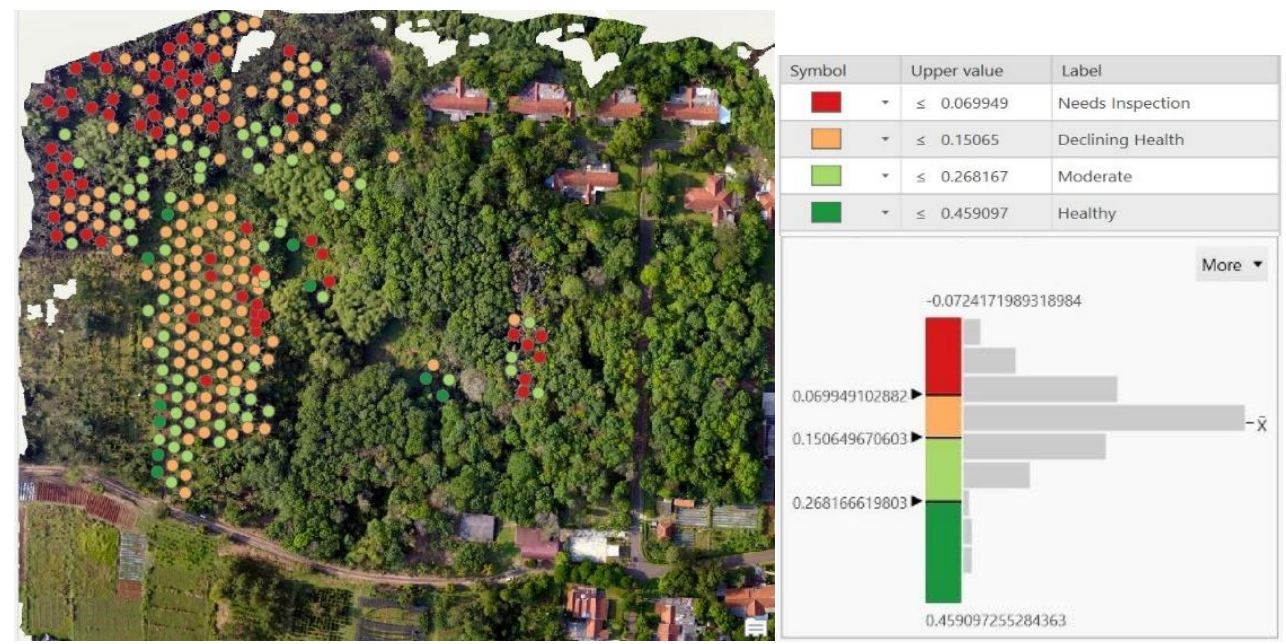

Fig. 8. Oil palm tree health map. (Data Processing)

\section{Conclusion}

The conclusion of this research is that the health of oil palm plants can be detected by utilizing aerial photographic images taken with UAV DJI Phantom 4 by calculating the Visible Atmospherically Resistant Index (VARI). If the plant is quickly detected as unhealthy, it will be quickly checked. So that aerial photography technology will save time and effort in monitoring the health of oil palm.

\section{References}

1. USDA. The Natural Resources Conservation Service 2019: The PLANTS Database National Plant Data Team Greensboro NC 27401-4901 (2019)

2. H.S. Saroinsong, V.C. Poekoel, and P.D. Manembu, Design of Unmanned Aircraft Vehicle Based on Ardupilot, Journal of Electrical and Computer Engineering. 7, 1 (2018)

3. R.P. Breckenridge, and M. E. Dakins, Evaluation of bare ground on rangelands using unmanned aerial vehicles: A case study GIScience, Remote Sensing. 48, 12 (2011)

4. J.N. Hird, A. Montaghi, G.J. McDermid, J. Kariyeva, B.J. Moorman, S.E. Nielsen and A.C.S. McIntosh, Use of unmanned aerial vehicles for monitoring recovery of forest vegetation on petroleum well sites, Remote Sensing. 9, 413 (2017)

5. V.G. Ambrosia, S.S. Wegener, D.V. Sullivan, S.W. Buechel, S.E. Dunagan, J.A. Brass, and S.M. Schoenung, Demonstrating UAV-acquired real-time thermal data over fires, Photogramm. Eng. Remote Sens. 69, 4 (2003)

6. J.P. Dash, M.S. Watt, G.D. Pearse, M. Heaphy, and H.S. Dungey, Assessing very high-resolution UAV imagery for monitoring forest health during a simulated disease outbreak ISPRS, Journal of Photogrammetry and Remote Sensing 131 (2017)

7. C.A. Rokhmana, The Potential of UAV-based Remote Sensing for Supporting Precision Agriculture in Indonesia in Ist International Symposium on LAPAN-IPB Satellite (2014) 
8. H.A. Afif, R. Saraswati, and R. Hernina, UAV Application for Landslide Mapping in Kuningan Regency, West Java in E3S Web of Conferences EDP Sciences. 125 (2019)

9. A. Syetiawan, and H. Gularso, Establishment of DSM Using Unmanned Aircraft System (UAS) and Non-Metric Digital Cameras in the National Seminar on Geography and Sustainable Development. (2018)

10. ArcGIS Learn, https://learn.arcgis.com/

11. A.A. Gitelson, Y.J. Kaufman, R. Stark, and D. Rundquist Novel algorithms for remote estimation of vegetation fraction, Remote sensing of Environment. 80, 1 (2002) 